\title{
Conversation Strategies and Communicative Competence
}

Christian Jones

Candlin \& Mynard ePublishing Hong Kong 
Published by Candlin \& Mynard ePublishing Limited

Unit 1002 Unicorn Trade Centre

127-131 Des Voeux Road Central

Hong Kong

ISBN: 9798720382643

Conversation Strategies and Communicative Competence

Copyright 2021 Christian Jones

Candlin \& Mynard ePublishing Limited was founded in 2012 and is incorporated as a limited company in Hong Kong (1830010). For further information, please see the website: http://www.candlinandmynard.com

Cover image: Myoko winter mountains by 雷太 (licensed under CC BY 2.0)

This book is copyright material and may not be copied, reproduced, printed, distributed, transferred or used in any way that contravenes the relevant copyright law without written permission from the publishers.

\section{CANDLIN \&MYNARD}




\section{Contents}

Acknowledgements 2

Preface by Tim Murphey, Series Editor 4

About the author $\quad 5$

Foreword by Jeanne McCarten and Michael McCarthy 6

Preamble 9

Introduction 11

CHAPTER 1

What are Conversation Strategies and Why Teach Them? 14

CHAPTER 2

Study 1: Corpus Analysis 32

CHAPTER 3

Study 2: Materials Evaluation $\quad 59$

CHAPTER 4

Study 3: Mixed-Methods Study in an ESL Context 97

CHAPTER 5

Study 4: Action Research Study in an EFL Context 132

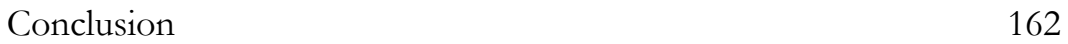




\section{Acknowledgements}

This book is dedicated to the late Ron Carter, who helped and inspired so many people in the field of Applied Linguistics and English language teaching. Ron was a fantastic PhD supervisor and mentor to me (and many, many others) and I hope that the work here is a tribute to him in some small way.

It is probably not possible to thank everyone, but I gratefully acknowledge the support, inspiration or friendship of the following people in the past and present: Svenja Adolphs, Marco Antonini, Nick Carter, Ron Carter, Jane Cleary, John Cross, Isabel Donnelly, James Donnithorne, Andy Downer, Graham Ethelston, Nick Gregson, Patrycja Golebiewska, Nicola Halenko, Tania Horak, Douglas Hamano-Bunce, Simon Hobbs, Stuart Hobbs, Nektaria Kourtali, Josie Leonard, Fergus Mackinnon, Hitomi Masuhara, Jeanne McCarten, Michael McCarthy, Tara McIlroy, Marije Michel, Alan Milby, Carmel Milroy, Emma Moreton, Jo Mynard, Clive Newton, David Oakey, Sheena Palmer, Simon Pate, Raymond Pearce, Lesley Randles, Scott Shelton-Strong, Paul Simpson, Karen Smith, Scott Thornbury, Ivor Timmis, Neil Walker, Nicola Walker, Daniel Waller, Andy Williams, Dave Willis.

Thanks to Jeanne McCarten and Michael McCarthy for the foreword and to the participants in each study.

Special thanks to Douglas Hamano-Bunce for initial comments on the manuscript, Katie Hudson for teaching the classes in chapter 4, Jo Mynard for help with data collection in chapter 5 and Ziad Almaki and Zhiming Yang for help with data collection in chapter 4.

Finally, thanks to my family both near and far way, for all of their peace, love and understanding. 
The aim of science is not to open the door to everlasting truth, but to set a limit on everlasting error.

Bertolt Brecht 


\section{Preface from the Series Editor}

\section{Conversation Strategies and Communicative Competence}

presents four recent studies on the use of conversation strategies and how they affect students' communicative competence and then shows you how to use the activities in your own classes, and possibly do your own research if desired. The author Christian Jones presents and analyses conversation strategies across the spectrum from low-level learners to advanced and native speakers, and very appropriately advises us how to help our students acquire and use valuable strategies in interactive and ecological procedures in our own classrooms. He also includes the research background that any $\mathrm{MA}$ or $\mathrm{PhD}$ student would need to further study and promote conversation strategies (and I hope that many will).

Jones valuably starts with an overview of what conversation strategies actually are and why we should teach them. He then presents us with a detailed corpus analysis along with teacher evaluations of materials for teaching conversation strategies. He then guides you through two studies with actual students in the classroom in ESL and EFL contexts. Seldom are readers given so many valuable tips, research insights, and pedagogical pathways in conventional research articles; Jones has done a good job of combining good research with valuable pedagogical praxis.

Tim Murphey

\section{The positive pedagogical praxis series}

Books in Candlin \& Mynard's Positive Pedagogical Praxis Series focus on practical activities, procedures and principles that can create more profound learning in a variety of ways. The books are written in a teacher-friendly style and seek to provide teachers with ways to implement profound ideas into their classrooms. The books could be used for in-service training, professional development workshops and teacher-development.

\section{https://www.candlinandmynard.com/ppp.html}




\section{About the Author}

Christian Jones is a Senior Lecturer in Applied Linguistics and TESOL at the University of Liverpool, UK. He has been involved in English language teaching for over twenty-five years and has worked in China, Japan, Thailand and the UK. During this time, he has taught general English, business English, exam classes, classes for young learners and undertook materials/course development and teacher training. He holds the Cambridge CTEFLA and DTEFLA qualifications alongside an $\mathrm{MA}$ and $\mathrm{PhD}$ from the University of Nottingham.

His main research interests are related to spoken language and he has produced work on spoken corpora, lexis and lexico-grammar, classroom applications of corpus data and instructed second language acquisition. Recent publications include: Jones, C., Byrne, S., \& Halenko, N. (2018). Successful spoken English: Findings from learner corpora (Routledge); Literature, spoken language and speaking skills in second language learning (2019) and Practice in second language learning (2018) (both as editor, Cambridge University Press). 


\section{Foreword}

This is a much welcome and timely book that will be of enormous interest to anyone involved in researching and teaching the spoken language in any context. We are delighted to see it published, not just because its rationale, aims and research agenda are dear to our own hearts as language researchers and ELT materials writers, but because it seeks empirical evidence to support the case for successful teaching of conversation strategies, evidence, which in our own case at least, while overwhelmingly positive, has been up to now largely anecdotal.

In the late 1990s as we and our co-author, Helen Sandiford, planned the materials which were subsequently published as Touchstone from 2005 and Viewpoint from 2012, we were well aware of the problem Christian Jones describes in the preamble, i.e., that students' 'conversations stubbornly refused to develop much beyond question and answer sequences.' To address this, we developed a syllabus strand that we hoped would enable students, even at beginner levels, to engage successfully in the interactive practice that we call 'conversation' as opposed to the vaguer notion of 'speaking.' This meant developing, with the aid of spoken corpora, a new repertoire of language items (e.g., discourse markers, hedges) and techniques (e.g., asking follow-up questions, pre-closing) and a methodology to explicitly deliver them. Any initial scepticism by teachers who had not seen discourse markers such as 'I mean' in teaching materials or had dismissively referred to them as 'fillers' soon gave way to positive feedback. The hundreds of personal interactions we have had with teachers over the years suggest that teaching conversation strategies really does help learners communicate more effectively, and moreover, that learners and teachers perceive their value. However, this feedback remains at the level of personal communication and by word of mouth.

It is therefore enormously pleasing to see a book which addresses some important research questions in this area including: whether the teaching of conversation strategies is seen as a viable option by teachers working in a range of contexts, to what extent explicit instruction of conversation strategies enhances participants' ability to use them, how learners and ELF speakers use conversation 
strategies, and whether participants in the studies perceive conversation strategies as useful tools to develop more successful conversations outside of class. These are all valuable questions to seek answers to and the results are instructive.

In Chapter 3 we learn that teachers in different contexts have generally positive attitudes towards a focus on spoken language and teaching conversation strategies. This is important for it is teachers who are the key to successful teaching; they need to believe in the value of the content they are sharing with their learners for it to be effective.

One of the most persuasive aspects of the studies in this book is the prominence of the voice of the learners in the extracts from the learning diaries. So often we approach corpus-informed materials research from a quantitative perspective, number crunching frequencies of words, chunks and patterns or 'before' and 'after' instruction test scores. While these are descriptively and pedagogically illuminating, it is both refreshing and instructive to see in the qualitative data so many comments from actual learners in ESL and EFL contexts. In particular the responses of ESL students in Chapter 4 Study 3, whose language needs we might mistakenly identify as predominantly 'survival' or transactional in nature, show that, on the contrary, they perceive the value of the interpersonal role of conversation strategies. The value these learners attach to this area may also be partly demonstrated by their striking ability to remember not only what they had been taught but also how they had been able to use it outside the classroom. This also shows an impressively high degree of linguistic self-awareness. Similarly, in Chapter 5 Study 4, the Japanese EFL learners report the usefulness of conversation strategies, but interestingly, in connection with reducing the anxiety they felt when called upon to speak; the affective factor in language learning should not be underestimated. Further, these learners considered that the explicit teaching of conversation strategies enabled them to express themselves both better and more naturally, a judgement which surely encapsulates the ultimate aim of all language teaching.

While humbly recognising the limitations of his research studies, Christian Jones draws useful implications to inform the development of materials and inspires a number of avenues for fruitful future research into the teaching of conversation strategies. 
We congratulate him on this volume and wish him and anyone connected with conversation strategy teaching huge success. The manifestations of their success will, no doubt, speak for themselves.

Jeanne McCarten

Michael McCarthy 


\section{Preamble}

When I began teaching (in Japan, in 1993) I came across many learners who wanted to improve their spoken English. They sometimes had the impression that simply by practising the grammar that junior high schools had filled their heads with, often in the dreaded 'conversation' class, their conversation skills would develop naturally. Sadly, they didn't. Looking back, I was aware of this but often lacked the skills to help them effectively. My initial training, while excellent and inspiring in many ways, had suggested that teaching functional exponents, vocabulary or items of grammar such as 'going to' would enable learners to use this in their own conversations, through such methods as contextualisation, concept checking, personalisation and repetition. Of course, I am sure this did help learners to some degree, but I was often left wondering at how their conversations stubbornly refused to develop much beyond question-and-answer sequences. I am not naïve enough to believe that this was solely down to me and am aware of the many factors which may have contributed to this: lack of input, lack of opportunities for interaction in English and motivation being just three of those.

These questions stayed with me and after time, led to reading a seminal article on spoken grammar (McCarthy \& Carter, 1995) and then a book (Carter \& McCarthy, 1997), both of which gave clear descriptions of spoken language, based on corpus evidence. Eureka! It seems so obvious now. But the revelation that spoken language (especially when used in conversations) has some fundamental differences to written language and that these differences can be described was a breakthrough moment, for me anyway. I understood that we cannot hope to help learners develop good conversation skills if we base teaching on written models, and that we need to understand the interactional and interpersonal nature of conversation. As a previous manager of mine (who shall remain nameless) was fond of saying, this was not rocket science, but it definitely opened a door to me, changing how I thought about language and teaching. Meanwhile, I looked back at some of my old lessons with a creeping despair. All of this sparked an interest which led first to postgraduate and then doctoral study at the University of Nottingham (where Ron Carter and 
Mike McCarthy were based) and to a continuing interest in how to help learners to develop spoken language in conversations. This book is the result of that. It represents an investigation into one possible approach aimed at helping learners develop more successful conversations: teaching conversation strategies and the language needed to realise them. I do not claim that this is the only approach or that I have found all the answers - that would be foolish. Research is often about trying to find an answer, being clear on the limits it has and then thinking how we might develop or test that further. I hope that this book achieves at least this. 


\section{Introduction}

One central aim of Communicative Language Teaching (CLT) is that those employing it seeks to help learners develop communicative competence, a concept first developed by Hymes (1972). In order to do this, speaking practice of various forms has often been foregrounded in CLT methodology (used interchangeably with the terms 'communicative methodology/approach/approaches' in this book), in the hope that this will develop communicative competence and therefore the ability to have successful conversations in L2 English. We can, however, question the extent to which syllabuses and common activity types actually do this. We might ask, for example, how many communicative activities actually develop learners' ability to move, in Thornbury's (2005) terms, 'beyond the sentence' or how many are actually based on an analysis of spoken language.

In the last twenty-five years or so, researchers in corpus linguistics (e.g., Carter \& McCarthy, 2006, 2017) have done much to describe the most common linguistic and discourse features of conversation, which give us evidence of the forms and functions speakers use when they speak (e.g., Carter \& McCarthy 2006, 2017; Jones et al., 2018; Tao, 2003). We now know what native speakers and successful learners say and do when they have conversations, and this is slowly starting to be reflected in teaching materials (e.g., McCarthy et al., 2014). However, as useful as these descriptions are, it is not always clear the extent to which they translate to second or foreign language classrooms, materials and methodology. Burton (2019), for example, argues that the 'cannon' of established pedagogic grammar, as often reflected in textbooks can be impervious to corpus findings and many of us will of course be able to produce examples of stilted and unnatural dialogues in published materials. Regarding methodology and syllabus design, McCarthy and McCarten (2018) suggest that what is termed 'speaking practice' within CLT does not always reflect these findings from spoken corpora. As an example, learners are often given practice of language items at the sentence level, in the hope that they will be able to transfer this into speaking turns and interactive conversation. McCarthy and McCarten (2018) argue against such an approach. They suggest that learners are more 
likely to develop the ability to have successful conversations if teaching is based on information from corpora and focuses on common conversation strategies (such as showing good listenership) and the language used to realise them. Their work details how such strategies and the language we use for them can be used as an organising principle for conversation syllabuses.

McCarthy and McCarten's (2018) suggestions are persuasive and form one strand of a successful coursebook series (e.g., McCarthy et al., 2014). However, as yet, there is only limited evidence that these ideas have been tested by researchers. The aim of this book is a modest attempt to fill this gap and offer teachers and researchers the start of an evidence base to show the effects of conversation strategies on the communicative competence of both ESL and EFL learners. It is also an attempt to show how different research designs, using quantitative and qualitative data, can be employed to investigate one area in different ways and so provide clearer, more reliable results. Such an approach could of course be applied to other areas which may interest teachers or researchers.

The book begins by introducing the arguments for teaching conversation strategies as a means of developing communicative competence, expanding on some of the ideas mentioned in this brief introduction. This chapter defines key terms and positions this book's aims and arguments. The next four chapters each describe a different study examining the teaching of conversation strategies in a different way: a learner corpus investigation of strategies used by both learners and users of English as a lingua franca; a materials evaluation study based on the responses of teachers in a variety of contexts; an experimental study in an ESL context, comparing the effects of teaching conversation strategies to a control group receiving no instruction; and finally a qualitative diary and interview study in an EFL context. Following this, the concluding chapter discusses the implications of these studies for teachers and researchers. 


\section{References}

Burton, G. (2019). The canon of pedagogical grammar for ELT: A mixed methods study of its evolution, development and comparison with evidence on learner output. [Unpublished doctoral dissertation]. Mary Immaculate College, Limerick, Ireland.

Carter, R., \& McCarthy, M. (1997). Exploring spoken English. Cambridge University Press.

Carter, R., \& McCarthy, M. (2006). Cambridge grammar of English: A comprehensive guide: Spoken and written English grammar and usage. Cambridge University Press.

Carter, R., \& McCarthy, M. (2017). Spoken grammar: Where are we and where are we going? Applied Linguistics, 38(1), 1-20. https://doi.org/10.1093/applin/amu080

Hymes, D. (1972). On communicative competence. In J. B. Pride \& J. Holmes (Eds.), Sociolinguistics: Selected readings (pp. 269-29). Penguin.

Jones, C., Byrne, S., \& Halenko, N. (2018). Successful spoken English: Findings from learner corpora. Routledge.

McCarthy, M., \& Carter, R. (1995). Spoken grammar: What is it and how can we teach it? ELT Journal,49(3), 207-218. https://doi.org/10.1093/elt/49.3.207

McCarthy, M., \& McCarten, J. (2018). Now you're talking! Practising conversation in second language learning. In C. Jones (Ed.), Practice in second language learning (pp. 7-29). Cambridge University Press.

McCarthy, M., McCarten, J., \& Sandiford, H. (2014). Touchstone second edition, levels 1-4. Cambridge University Press.

Tao, H. (2003). Turn initiators in spoken English: A corpus-based approach to interaction and grammar. In P. Leistyna \& C. F. Meyer (Eds), Language and computers, corpus analysis: Language structure and language use (pp. 187-207). Rodopi.

Thornbury, S. (2005). Beyond the sentence: Introducing discourse analysis. Macmillan. 